\title{
Musculoskeletal ultrasonography in rheumatic diseases
}

\author{
Erhan ÇAPKIN*
}

*Department of Physical Medicine and Rehabilitation, Faculty of Medicine, Karadeniz

Technical University ,Farabi Hospital, Trabzon, Turkey

*Correspondence: drcapkin@yahoo.com

ORCIDs: https://orcid.org/0000-0003-2728-5934

\section{Acknowledgement/Disclaimers/Conflict of interest}

None of the authors of this paper has any financial or personal relationship with other people or organizations that could inappropriately influence or bias the content of the paper. 


\section{Musculoskeletal ultrasonography in rheumatic diseases}

Ultrasonography is an imaging technique that is used for evaluation of soft tissues based-on utilization of sound waves. Sound waves has been used for a long time in non-medical field including military defense systems, radar systems and detection of icebergs. In association with the technological advances inventions in medical imaging has been achieved and new techniques including magnetic resonance imaging, ultrasonography, computed tomography became available. Nowadays, imaging techniques has become as a gold standard protocol in diagnose of many diseases. Recently developed diagnose and therapy options provides more efficient treatment of rheumatic diseases. Thus, it became possible to prevent structural damages and disabilities. Musculoskeletal ultrasonography is becoming a preferred choice of imaging technique for rheumatic diseases, with many advantages. Among its advantages includes being cheap, radiation-free, dynamic image capacity, and capacity of detection of disease activity, early diagnosis and early detection of structural damages. This review summarizes use of ultrasonography in rheumatic diseases.

Keywords: Musculoskeletal ultrasonography, rheumatoid arthritis, spondyloarthropathies, crystal arthritis 


\section{Introduction}

Ultrasonography (US) is based on the creation of sound waves at a frequency that the human ear cannot hear, sent to the body through probes and reflected from the tissues as images on the screen through an operating system. This principle is called the piezoelectric principle. The use of sound waves in imaging is goes back to very early years. It has been used in many fields including defense systems, radars, and detection of icebergs. In the 19th century, it started to be used in medicine and health services [1]. A study was published for the first time in the 1940s about the use of US in detection of breast nodules. Later on US started to be used for diagnosing over cyst and in the following years, many clinicians started to publish many papers about US use in their own branch [2]. The first article in the literature on its use in musculoskeletal diseases was published in 1972, where it was used for differential diagnosis of Baker's cyst with thrombophlebitis [3]. Sound waves reflected from tissues in US are transferred to an operating system via a probe. The image is formed in a range of black and white colors according to the reflective properties of the textures. The image formed in ultrasonography is described by the concept of echogenicity. Liquids are seen as black (anechoic) because they pass all sound waves, while bone tissue is seen as white (hyperechoic) because it reflects all of the sound waves that expose to it (Table 1). There are various modalities in US evaluation. Gray scale is the most commonly used mode. Also known as B mode, the image is in the range of black and white. Color doppler showing blood flow and M mode is used mostly in the cardiovascular system. Power doppler (PD) mode is used in rheumatology to show the smaller microvascular bed, especially synovial blood supply. PD is particularly important in demonstrating disease activity and determining prognosis. Probes with many different features are used in the evaluation of US. Linear probes are generally sufficient to evaluate the musculoskeletal system. Convex probes can be preferred to evaluate deep tissues such as hip and sacroiliac joints. Although the frequency range of the probe varies according 
to the tissue to be imaged, high frequency probes should be used in superficial tissues and low frequency probes in deep tissues [1]. US has been increasingly used by clinicians in many stages of many rheumatic diseases such as diagnosis, follow-up and interventional procedures, especially inflammatory diseases. Various recommendations regarding the use of US in rheumatic diseases have been presented in many international guidelines.

\subsection{Detection of pathologies by ultrasound}

OMERACT is a study group consisting of the initials of Outcome Measures in Rheumatoid Arthritis Clinical Trials, which defines the outcome measurement methods used in clinical studies in rheumatology. In 2005, a definition proposal was made for the pathologies seen in US in inflammatory arthritis. This recommended is currently used in patient descriptions [4]. According to the recommendations of this study group, the pathologies seen in inflammatory diseases are defined as follows:

Synovial fluid: Abnormal hypoechoic or an anechoic (relative to subdermal fat, but sometimes isoechoic or hyperechoic) intra-articular material that is displaceable and compressible, but does not exhibit Doppler signal (Figure 1a,1b)

Synovial hypertrophy: Abnormal hypoechoic (relative to subdermal fat, but sometimes isoechoic or hyperechoic) intra-articular tissue that is non-displaceable, poorly compressible, and may exhibit Doppler signal in relation to disease activity (Figure 2a,2b).

Enthesitis: It is defined as bone changes such as abnormal hypoechoic appearance (loss of normal fibrillar structure), thickening (sometimes may include hyperechoic foci compatible with calcification), cortical bone loss, new bone formation in the bone adhesion area of the tendon or ligament. It can give a doppler signal (Figure 3). 
Tenosynovitis: In both planes, hypoechoic or anechoic thickening of the tendon with or without anechoic synovial fluid around the tendon is associated with disease activity and may exihibit Doppler activity (Figure $4 \mathrm{a}, \mathrm{b})$.

Erosion: It is the loss of cortical continuity on the bone surface. This cortical discontinuity should be shown in both axial and longitunal imaging (Figure 5 a,b).

A semi-quantitative scoring system is often used to determine disease activity. This is done in scoring systems both in gray scale and power doppler scale. Synovitis and tenosynovitis are generally classified separately. In this system, it is defined between 0 and 3 points as mild, moderate and severe. In a very recent classification for rheumatoid arthritis, gray scale and doppler scale have been combined [5]. (Table 2)

\section{Ultrasonography in Rheumatoid Arthritis}

Rheumatoid arthritis (RA) is the most common inflammatory rheumatic disease. The disease, which starts in the synovium at the beginning, affects all the structures of the joint and causes structural damage and disability. Early recognition and treatment of the disease reduces the risk of structural damage. Effusion, synovial hypertrophy, tenosynovitis and erosions seen in RA patients can be detected at early disease stage with US. The first regions usually involved in RA are wrists, metacarpophalangeal (MKF) and metatarsophalangeal (MTP) joints [6]. The main criterion for applying the classification criteria made according to the 2010 EULAR (European Rheumatology Association) / ACR (American Rheumatology Association) criteria is the presence of synovitis in a joint [7]. Here, swelling is an important criterion. The 2016 EULAR early arthritis guideline recommends that if arthritis is suspected in a joint, it should be confirmed by ultrasonography [8]. Studies have shown that US is superior to clinical examination and in detecting fluid in the joint. Especially in individuals presenting with the complaint of joint pain, US makes significant contributions to the point whether the pathology 
is caused by extra-articular structures (Figure 6). Synovitis is the most basic finding of RA. Early synovitis indicates the period when synovial inflammation begins but clinical signs do not appear. As a result of proliferative synovitis, the synovial membrane thickens and becomes a hypertrophic, hyper-vascular tissue, and structural damage begins to occur with many proinflamataur cytokines released into the environment. At this stage of the disease, it is impossible to evaluate these changes in soft tissues with X-rays. US can provide valuable information at this early stage of the disease. Demonstration of synovitis in early RA studies, sensitivity increased to $78 \%$, specificity of $79 \%$, clinical examination sensitivity $58 \%$, specificity $78 \%$, and specificity was increased even further if US synovitis is taken as grade 2 and above in patients with US grade 1 and above synovitis scores [9]. In this respect, US has a very important place in detecting synovitis at the early stage of the disease. In a study conducted in another cohort (ESPOIR cohort), US sensitivity was $74 \%$ and specificity was $90 \%$ in patients with a synovitis score of grade 2 and above [10]. Results of many studies indicates that US is a superior imaging method compared to US clinical examination and X-ray at the early stage of the disease. In addition, information about the severity of synovitis can be obtained with PD activity [11]. It has also been shown that the findings obtained with US are correlated in comparative studies with MRI [12]. Disease activity is very important for the development of structural damage. The high number of sensitive and swollen joints and high acute phase indicators can provide us a prediction. In addition, US also helps us about detecting the activity of the disease. Particularly, PD signals indicating increased blood supply and their severity are correlated with the activation of the disease. In many studies, activation detected by US was found to be correlated with disease activity [13-15]. Subclinical inflammation can be demonstrated with US. The risk of relapse has been found to be higher in those with positive PD signals, especially in studies conducted in patients in clinical remission [16]. The main characteristic of imaging finding among RA is the development of erosion. US can show 
erosions at an early stage without being reflected on the X-ray For the first time, Backaus et al have shown in a clinical study that it detects the erosions better than US X-rays [17]. Following this study, US was shown to be superior in detecting erosion, especially in the early disease stage, in many studies $[18,19]$.US has been conducted in many studies on its use in the moniterization of the disease and in the evaluation of the response to treatment. Filippucci et al. evaluated the patients by US, before and after intraarticular steroid injection. They found a decrease in doppler signal as well as clinical response [20]. In a similar study Newman et al. Ultrasonographically demonstrated the reduction in synovial vascularization after anti TNF [21]. Similar results have been shown in different studies of biological agents [22-24]. As a result, US can be used effectively in evaluating the treatment response of the disease. In a disease with progressive characteristics such as RA, markers related to its progression are very important. Disease activity, the number of swollen joints, auto antibody positivity, and the presence of erosion are the most important prognostic markers known [25]. Many studies have been conducted on the prognosis of the disease with US. Taylor et al. In a study conducted with US in 24 early RA patients, they showed that patients with significant doppler signal in the early stage of the disease had more radiographic damage in these patients after 2 years of follow-up. As a result, they stated that the existing doppler signal in patients may have a predictive importance for the development of structural damage [26]. In a similar study, Naredo et al found a positive correlation between US scores and disease activity scores and radiographic progression in early RA. In another study by the same team with more patients, they showed that the power dopler signal in particular was blinded by activity and radiological progression [27]. Brown et al. In a study of 102 RA patients with subclinical disease activity, they showed that patients with metacarpophalangeal joints (MCP) synovial hypertrophy and doppler signal progressed radiographically [28]. Although the use of US in RA patients has many advantages, it is controversial to evaluate which joints in a disease with polyarticular involvement. 
However, different joint numbers have been defined in many joint scoring systems [29-32]. Scheel et al. 3 joints ( 2 th and 4 th MCF joints and palmar surfaces of the proximal interphalangeal joints (PIF) joints) [33], Naredo et al suggested 12 joints (2th and 3 th bilateral MCF, wrist, 2th and 3th PIF and knee) [34], Backhaus et al. (wrist, 2th and 3th MCF and PIF, 2th and 5th Metatarsophalangeal joints(MTF) evaluation would be sufficient for the hand and foot, and it was recommended to examine the intensity of the gray scale synovitis, tenosynovitis, and doppler signal [35]. In this scoring system, they defined it as the German US 7 score. They proposed this scoring system for use in daily practice and studies [36]. Considering these scoring systems, recommended in daily practice, first of all, evaluation of the joint with the patient's complaint, as well as bilateral examination of the most frequently affected wrist, 2 th and 5 th MKF in the hand, 2 th and 5 th MTF joints in the foot, both in gray scale and doppler. It is the evaluation of these joints in terms of signal. Ultrasonography can be used as a guide for local injections in patients with RA. US is used as a guide for local injections in many musculoskeletal diseases. US-guided injections are more effective and the risk of side effects is lower with this procedure [37,38]. Similar results have been shown in injection studies with RA [39-42]. It is stated in EULAR RA imaging recommendations that it can be used in the evaluation of US remission. In a meta-analysis of 1639 patients including 19 studies on this subject, the majority of patients (1369 patients) consisted of patients in clinical remission. While $80 \%$ of these patients had US findings in the gray scale, $44 \%$ of them had positive synovitis in both the gray scale and the PD scale. Is clinical remission true remission in these studies raised the question. Although the debate on this issue continues, relapse rates are higher, especially in patients with positive PD signals. In this respect, it may be an option to evaluate patients with US in drug reduction or cutting. But more clinical studies are needed on this subject (Figure 7a,b) [43]. In two current strategy studies about the use of US in treatment management; While deciding on the choice of treatment, the role of US was taken into 
consideration. Patients were randomized into two groups. Clinical scores and drug changes were performed in one arm, and the patients were similar to clinical scores in the other arm, and US was used together with the clinic for drug change. Patients were evaluated at frequent intervals in both arms. While there was no significant difference in activity scores in the US arm compared to the clinical arm, it showed less progression in radiological scores. More medication was used in the US arm. Although its role in US treatment decision is controversial, it has been emphasized that studies on this design are needed in larger series $[44,45]$. As a result, as emphasized in the EULAR imaging guideline, ultrasound is an increasingly used important imaging method in the management of many stages of RA patients such as diagnosis and follow-up treatment selection [46].

\section{Ultrasonography in Spondyloarthropathies}

There has been a serious change in the terminology of spondyloarthropathies (SpA) in recent years. This group of diseases has been classified in two categories. Axial spondyloarthritis (Ankylosing spondylitis and non-radiographic axial $\mathrm{SpA}$ ) with more involvement of the axial spine and peripheral SpA (Psoriatic arthritis, reactive Arthritis, Undifferentiated arthritis and inflammatory bowel disease-related arthritis) with more prominent peripheral involvement. Many methods are used to monitor these diseases. Although MR is a gold standard method in axial disease, ultrasonography is a very important method in the evaluation of arthritis, enthesitis, tenosynovitis and dactylitis in peripheral involvement [47]. In the SpA EULAR imaging guideline, in peripheral SpA US is recommended to be used in the diagnosis, followup, and evaluation of structural damage [48]. Evaluation of synovitis with peripheral SpA is evaluated in a similar way to RA. Synovial hypertrophy, effusion, and doppler activity are defined similar to evaluations made in RA patients. Tendon involvement, tendon-bone junction is considered to be a very important target organ for SpA. US is the gold standard method for the evaluation of these structures. In disruption in the tendon fibrillar structure and tendon 
thickening, hypoechoic areas and increased doppler activity are observed. Dactilitis is an important clinical finding especially in PsA patients. In addition to joint involvement, oedema in soft tissue and thickening of tendons are seen on ultrasonography [49]. Enthesitis is a characteristic finding of SpA patients. Pain and tenderness at the bone attachment site of tendons and ligaments are typical findings. It is mostly seen in the Achilles region. Clinically, sensitivity in palpation in this region is the most basic examination finding. US evaluation of this region is very important for active SpA patients. According to ASAS (International Society of Ankylosing Spondylitis) and GRAPPA (Psoriasis and Psoriatic Arthritis Working Group), the presence of enthesitis is considered both a diagnostic and an activation indicator. First study with US in 1994 by Lehtinen et al. the changes seen in this region by US have been described on a gray scale. In the following years, many studies have been conducted on the use of gray scale and doppler scale together [50]. In the early stage of the disease, in differential diagnosis (especially from fibromyalgia), tendon echogenicity deterioration, hypoechoic areas increase in doppler activity and erosions in the bony cortex are observed in US [51]. Although it has been shown in many studies that there is a correlation between disease activity, clinical enthesitis scores and US images, there are articles emphasizing that there are conflicting results. But how often there is no consensus on the assessment of the patient [52-54]. The use of various scoring systems for the assessment of the enthetical region has been proposed [55]. As a result, the use of US in the diagnosis of SpA, especially in the diagnosis of peripheral involvement, is considered as a method that greatly contributes to the clinician. The use of US is recommended in EULAR imaging recommendations.

\section{Ultrasonography in Crystal Arthropathies}

US is frequently used in the diagnosis of crystal-associated arthritis. When crystal arthritis is mentioned, the first disease that comes to mind is Gout, in which mono sodium urate crystals accumulate. It is one of the most common inflammatory diseases. In pathogenesis, the 
disease develops as a result of the accumulation of urate crystals in the joints and surrounding structures and triggering the inflammatory process. The definitive diagnosis is to show these accumulated crystals microscopically. This may not be possible for every patient, or crystals may not be visible in a polarized microscope in $25 \%$ of patients. In recent years, new methods of imaging have been used to facilitate the diagnosis of this disease. Dual energy computed tomography and US are the leading methods. These crystals are not visible on X-rays. With US, these crystals are seen as hyperechoic and shiny. Symptoms of synovitis that develop in the early stage of the disease are seen in the joint space as increased joint fluid and synovial hypertrophy and increased doppler activity [56]. Urate crystals usually accumulate on the cartilage surface and US is defined as a double contour image to this typical image (Figure 8a,b,c,d ) [57]. The OMERACT group defined US findings in gout as 4 main findings. These have been defined as double contours, tophi, aggregates and erosion. The double contour is the image formed by the crystals deposited on the joint surface. Unlike calcium pyrophosphate, it accumulates on the joint surface. Aggregates are crystal deposits that do not give acoustic ghosting, which are deposited in the joint space or in the soft tissue. Tophi accumulates in the joint or soft tissue, acoustic shadowing is usually not observed. In erosions, RA similar definition has been made, differently, an erosion definition has been made that can include soft tissues rather than a single erosion that can also include soft tissues [58]. US findings have a point value in scoring made in the new gout classification criteria $[59,60]$. In studies conducted with US findings in the diagnosis of the disease, the specificity of the double contour image was found to be quite high $(98 \%)$. In studies on its sensitivity, different results have been reported in the range of $22 \%$ to $91 \%$ [61,62]. Erosions seen on X-rays in the late stages of the disease can be detected earlier with US. It has been shown to be more sensitive in comparative studies with conventional radiographs [63]. Studies on MRI and tomography have shown that these two methods are superior to US in detecting erosion [64]. US can be used in the follow- 
up of the disease. Especially, double contours and tophi can be followed. Small studies have shown regression in US findings after urate-lowering therapy [65]. Clinical response to US after colchicine treatment was found to correlate with clinical response in the joint, as well as decreased US findings [66]. Another crystal storage disease, calcium pyrophosphate dihydrate disease, can be seen by US in the crystals deposited here (Figure 9). In the early period, deposits that cannot be seen on X-ray can be demonstrated by US. Unlike gout, accumulated crystals are seen in the cartilage, menisceal structures $[67,68]$. It has been shown in studies performed with $\mathrm{X}$-ray that it is superior, especially in the early period. (Interestingly, although there is calcium in the accumulated crystals, unlike other calcific deposits, post-acoustic shading is not seen in these crystals $[69,70]$. There is more deposition in fibrocartilage structures compared to hyalene cartilage [71].

\section{Ultrasonography in Polymyalgia Rheumatica}

It is a common inflammatory rheumatic disease characterized by high sedimentation rate and CRP levels, pain and stiffness in the muscles of the shoulder and hip girdle. Diagnostic difficulties may be present in patients with an unclear acute phase response. US is useful in diagnostic terms in these patients. Disease activation correlates with US findings. In US, fluid is seen in the biceps tendon sheath, glenohumeral and hip joints. Tenosynovitis and doppler activity may be increased. This is an indicator of disease activation [72]. In addition to clinical findings, US findings are also included in the classification of new diagnostic criteria [73]. Improvements were also detected by US after steroid therapy, which is one of the follow-up studies (Figure 10 a,b). 


\section{Ultrasonography in degenerative diseases}

X-ray still maintains its importance in degenerative joint diseases. Thinning of cartilage, increase in joint fluid, and osteophyte formations can be seen in US (Figure 11). Calcium crystals may be seen accumulating in OA patients US guidance is often used for local injections in US patients [74]. Although EULAR recommends the use of US in OA imaging recommendations, especially in the early stage of the disease and during synovitis attacks, in terms of showing soft tissue changes and injection guidance. For now, still maintains its importance in OA patients. It has been stated that advanced imaging methods can be used in atypical cases, rapidly progressive patients and in the above-mentioned conditions [75].

\section{Use of Ultrasonography in other rheumatic diseases}

In addition to its use in rheumatic diseases that we frequently see in our daily practice, US is used today in rheumatic diseases that are less common. Among these diseases, it helps in diagnosis, especially in large vessel vasculitis. Temporal artery US helps diagnosis in giant cell arteritis. Homogeneous thickening of the vascular wall and hypoechoic areas as well as decreased blood flow are findings that can be seen with US [76.77]. In Sjögren's syndrome, impaired echogenicity in the parotid and submandibular glands and the presence of hypoechoic foci help the diagnosis. Adding sonographic findings to clinical diagnostic criteria increases the diagnostic probability [78]. In systemic sclerosis, skin evaluation can be performed with highfrequency probes [79].

\section{New US modalities}

In addition to the gray scale and Power dopler methods we use today, there are new developments in US. 3D, elastography and hybrid systems are the main ones. 3D imaging is a new US modality that can be used especially for detecting erosions and quantitative measurement of doppler activity [80]. Elastography may provide additional contributions, 
especially in the evaluation of tendon pathologies, at an earlier stage. MRI or CT and US can be applied simultaneously. These methods are not currently in clinical practice and are new promising methods [81].

\section{US Advantages and disadvantages}

US is the most practical and fast method for imaging the musculoskeletal system. While it can be easily applied in the clinic and at the same time, multiple joints can be evaluated in real time. It allows dynamically examining the tissues. All structures located on the bone can be evaluated, depending on the capacity of the device and the characteristics of the equipment used. It can show needles and target structures in real time in interventional procedures. It can provide the opportunity to perform an effective interventional procedure without damaging the surrounding tissues and causing radiation exposure. (Figüre $12 \mathrm{a}, \mathrm{b}$ ). It provides the opportunity to compare with normal tissues simultaneously. Contributes increased effectiveness of the applied treatments. It gives the possibility to recognize many pathologies at an early stage. These are among its many advantages to mention. The biggest limitation is that it is a more user-dependent method compared to other imaging methods. The experience and training of the practitioner is very important in this respect. The inability to obtain multiple planed images, the inability to show the inside of the bone, the presence of anatomically inaccessible areas of sound waves, and additional time for clinical examination [82]. 


\section{REFERENCE}

1. WA Scmidt, G.A.W Bruyn. Musculoskletal ultrasound for Rheumatologist. 2th ed. Press media Nederlans bohn stafle van loghum Houten; 2011.

2.Donald I, Macgravir J, Brown T. Investigation of abdominal masses by pulsed ultrasonography. Lancet 1958; 7 1(7032):1188-1195. doi: 10.1016/s0140-6736(58)91905-6.

3. McDonald DG, Leopold GR. Ultrasound B-scanning in the differentiation of Baker's cyst and thrombophelebitis. British Journal of Radiology 1972; 45 (538):729-732. doi: $10.1259 / 0007-1285-45-538-729$.

4. Wakefield RJ, Balint PV, Szkudlarek M, Filippucci E, Backhaus M et al. OMERACT 7 Special In-terest Group. Musculoskeletal ultrasound including definitions for ultrasonographic pathology. Journal of Rheumatology 2005; 32(12):2485-2487.

5. D'Agostino MA, Terslev L, Aegerter P, Backhaus M, Balint P et al. Scoring ultrasound synovitis in rheumatoid arthritis: a EULAR-OMERACT ultrasoundtaskforce-Part 1: definition and development of a standardised, consensus-based scoring system. Rheumatic and musculoskeletal diseases Open 2017; 11 3(1): e000428. doi: 10.1136/ -2016-000428.

6. Smolen JS, Aletaha D, Barton A, Burmester GR, Emery P et al. Rheumatoid arthritis. Nature Reviews Disease Primers 2018; 8:4:18001. doi: 10.1038/.2018.1.

7. Aletaha D, Neogi T, Silman AJ, Funovits J, Felson DT et al. 2010 rheumatoid arthritis classification criteria: an American College of Rheumatology/European League Against Rheumatism collaborative initiative. Annals of the Rheumatic Diseases 2010; 69(9):1580-1588. doi: $10.1136 / 2010.138461$. 
8. Combe B, Landewe R, Daien CI, Hua C, Aletaha D et al. 2016 update of the EULAR recommendations for the management of early arthritis. Annals of the Rheumatic Diseases 2017; 76(6):948-959. doi: 10.1136/ 2016-210602.

9. Nakagomi D, Ikeda K, Okubo A, Iwamoto T, Sanayama Y et al. Ultrasound can improve the accuracy of the 2010 American College of Rheumatology/European League against rheumatism classification criteria for rheumatoid arthritis to predict the requirement for methotrexate treatment. Arthritis and Rheumatology 2013; 65 (4):890-898. doi: 10.1002/37848

10. Millot F, Clavel G, Etchepare F, Gandjbakhch F, Grados F et al. Investigators of the French Early Arthritis Cohort ESPOIR. Musculoskeletal ultrasonography in healthy subjects and ultrasound criteria for early arthritis (the ESPOIR cohort). Journal of Rheumatology 2011; 38(4): 613-620. doi: 10.3899/ 100379.

11. Keen HI, Brown AK, Wakefield RJ, Conaghan PG. MRI and musculoskeletal ultrasonography as diagnostic tools in early arthritis. Rheumatic Disease Clinics of North America 2005; 31(4):699-714. doi: 10.1016/.2005.07.002.

12. Szkudlarek M, Klarlund M, Narvestad E, Court-Payen M, Strandberg C et al. Ultrasonography of the metacarpophalangeal and proximal interphalangeal joints in rheumatoid arthritis: a comparison with magnetic resonance imaging, conventional radiography and clinical examination. Arthritis Research and Therapy 2006; 8(2): R52. doi: 10.1186/1904.

13. Scheel AK, Hermann KG, Ohrndorf S, Werner C, Schirmer C et al. Prospective 7 year follow up imaging study comparing radiography, ultrasonography, and magnetic resonance imaging in rheumatoid arthritis finger joints. Annals of the Rheumatic Diseases 2006; 65(5):595-600. doi: 10.1136/ 2005.041814.

14. Naredo E, Collado P, Cruz A, Palop MJ, Cabero F et al. Longitudinal power Doppler ultrasonographic assessment of joint inflammatory activity in early rheumatoid arthritis: 
predictive value in disease activity and radiologic progression. Arthritis and Rheumatology 2007; 15;57(1):116-124. doi: 10.1002/22461.

15. D'Agostino MA, Boers M, Wakefield RJ, Berner Hammer H, Vittecoq O et al. Exploring a new ultrasound score as a clinical predictive tool in patients with rheumatoid arthritis starting abatacept: results from the APPRAISE study. Rheumatic and musculoskeletal diseases Open 2016; 5 2(1):e000237. doi: 10.1136/ 2015-000237.

16. Naredo E, Valor L, De la Torre I, Montoro M, Bello N et al. Predictive value of Doppler ultrasound-detected synovitis in relation to failed tapering of biologic therapy in patients with rheumatoid arthritis. Rheumatology (Oxford) 2015; 54(8):1408-1414. doi: 10.1093/rheumatology/006.

17. Backhaus M, Kamradt T, Sandrock D, Loreck D, Fritz J et al. Arthritis of the finger joints: a comprehensive approach comparing conventional radiography, scintigraphy, ultrasound, and contrast-enhanced magnetic resonance imaging. Arthritis and Rheumatology 1999; 42(6):12321245. doi: 10.1002/1529-0131(199906)42:6<1232: >3.0.CO;2-3

18. Salaffi F, Gutierrez M, Carotti M. Ultrasound versus conventional radiography in the assessment of bone erosions in rheumatoid arthritis. Clinical and Experimental Rheumatology 2014; 32(1 Suppl 80): 85-90. Epub 2014 Feb 17.

19. Wakefield RJ, Gibbon WW, Conaghan PG, O'Connor P, McGonagle D et al. The value of sonography in the detection of bone erosions in patients with rheumatoid arthritis: a comparison with conventional radiography. Arthritis and Rheumatology 2000; Dec;43(12):2762-2770. doi: 10.1002/1529-0131(200012)43:12<2762: 3.0.CO;2.

20. Filippucci E, Farina A, Carotti M, Salaffi F, Grassi W. Grey scale and power Doppler sonographic changes induced by intra-articular steroid injection treatment. Annals of the Rheumatic Diseases 2004; 63(6):740-743. doi: 10.1136/ 2003.007971. 
21. Hau M, Kneitz C, Tony HP, Keberle M, Jahns R. High resolution ultrasound detects a decrease in pannus vascularisation of small finger joints in patients with rheumatoid arthritis receiving treatment with soluble tumour necrosis factor alpha receptor (etanercept). Annals of the Rheumatic Diseases 2002; 61(1):55-58. doi: 10.1136/ 61.1.55.

22. Iagnocco A, Perella C, Naredo E, Meenagh G, Ceccarelli F. Etanercept in the treatment of rheumatoid arthritis: clinical follow-up over one year by ultrasonography. Clinical Rheumatology 2008; 27(4):491-496. doi: 10.1007/s10067-007-0738-3.

23. Naredo E, Collado P, Cruz A, Palop MJ, Cabero F. Longitudinal power Doppler ultrasonographic assessment of joint inflammatory activity in early rheumatoid arthritis: predictive value in disease activity and radiologic progression. Arthritis and Rheumatology 2007; 57(1):116-124. doi: 10.1002/ 22461.

24. Iagnocco A, Filippucci E, Perella C, Ceccarelli F, Cassarà E. Clinical and ultrasonographic monitoring of response to adalimumab treatment in rheumatoid arthritis. Journal of Rheumatology 2008; 35(1):35-40. Epub 2007 Nov 15.

25. Muñoz-Fernández S, Otón-Sánchez T, Carmona L, Calvo-Alén J, Escudero A et al. Use of prognostic factors of rheumatoid arthritis in clinical practice and perception of their predictive capacity before and after exposure to evidence. Rheumatology International 2018; 38(12):22892296. doi: 10.1007/s00296-018-4152-8.

26. Taylor PC, Steuer A, Gruber J, Cosgrove DO, Blomley MJ. Comparison of ultrasonographic assessment of synovitis and joint vascularity with radiographic evaluation in a randomized, placebo-controlled study of infliximab therapy in early rheumatoid arthritis. Arthritis and Rheumatology 2004; 50(4):1107-1116. doi: 10.1002/ 20123.

27. Naredo E, Collado P, Cruz A, Palop MJ, Cabero F et al. Longitudinal power Doppler ultrasonographic assessment of joint inflammatory activity in early rheumatoid arthritis: 
predictive value in disease activity and radiologic progression. Arthritis and Rheumatology 2007; 57(1):116-124. doi: 10.1002/ 22461.

28. Brown AK, Conaghan PG, Karim Z, Quinn MA, Ikeda K et al. An explanation for the apparent dissociation between clinical remission and continued structural deterioration in rheumatoid arthritis. Arthritis and Rheumatology 2008; 58(10):2958-2967. doi: 10.1002/23945.

29. Wakefield RJ, Green MJ, Marzo-Ortega H, Conaghan PG, Gibbon WW et al. Should oligoarthritis be reclassified? Ultrasound reveals a high prevalence of subclinical disease. Annals of the Rheumatic Diseases 2004; 63(4):382-385. doi: 10.1136/ 2003.007062.

30. D'Agostino MA, Terslev L, Aegerter P Backhaus M, Balint P et al. Scoring ultrasound synovitis in rheumatoid arthritis: a EULAROMERACT ultrasound taskforce-Part 1: definition and development of a standardised, consensus-based scoring system. Rheumatic and musculoskeletal diseases Open 2017; 3(1):e000428. doi: 10.1136/ 2016-000428.

31. Terslev L, Naredo E, Aegerter P, Wakefield RJ, Backhaus M et al. Scoring ultrasound synovitis in rheumatoid arthritis: a EULAR OMERACT ultrasoundtaskforce-Part 2: reliability and application to multiple joints of a standardised consensus-basedscoring system. Rheumatic and musculoskeletal diseases Open 2017; 3(1):e000427. doi: 10.1136/ 2016-000427.

32. Dougados M, Jousse-Joulin S, Mistretta F, d'Agostino MA, Backhaus M et al. Evaluation of several ultrasonography scoring systems for synovitis and comparison to clinical examination: results from a prospective multicentre study of rheumatoid arthritis. Annals of the Rheumatic Diseases 2010; 69(5):828-833. doi: 10.1136/ 2009.115493.

33. Scheel AK, Hermann KG, Kahler E, Pasewaldt D, Fritz J et al. A novel ultrasonographic synovitis scoring system suitable for analyzing finger joint inflammation in rheumatoid arthritis. Arthritis and Rheumatology 2005; 52(3):733-743. doi: 10.1002/ 20939. 
34. Naredo E, Gamero F, Bonilla G, Uson J, Carmona L, Laffon A. Ultrasonographic assessment of inflammatory activity in rheumatoid arthritis: comparison of extended versus reduced joint evaluation. Clinical and Experimental Rheumatology 2005; 23(6):881-884

35. Backhaus M, Ohrndorf S, Kellner H, Strunk J, Backhaus TM. Evaluation of a novel 7-joint ultrasound score in daily rheumatologic practice: a pilot project. Arthritis and Rheumatology 2009; 61(9):1194-1201. doi: 10.1002/ 24646.

36. Backhaus TM, Ohrndorf S, Kellner H, Strunk J, Hartung Wet al. The US7 score is sensitive to change in a large cohort of patients with rheumatoid arthritis over 12 months of therapy. Annals of the Rheumatic Diseases 2013; 72(7):1163-1169. doi: 10.1136/ 2012-201397.

37. Karkucak M, Cilesizoglu N, Capkin E, Can I, Batmaz I et al. Education and Visual Information Improves Effectiveness of Ultrasound-Guided Local Injections on Shoulder Pain and Associated Anxiety Level: A Randomized Controlled Study. American Journal of Physical Medicine and Rehabilitation 2016; 95(1):9-14. doi: 10.1097/ 0000000000000305.

38. Ucuncu F, Capkin E, Karkucak M, Ozden G, Cakirbay H et al. A Comparison of the effectiveness of landmark-guided injections and ultrasonography guided injections for shoulder pain. Clinical Journal of Pain 2009; 25(9):786-789. doi: 10.1097/AJP.0b013e3181acb0e4.

39. Nordberg LB, Lillegraven S, Aga AB, Sexton J, Lie E. The Impact of Ultrasound on the Use and Efficacy of Intraarticular Glucocorticoid Injections in Early Rheumatoid Arthritis: Secondary Analyses From a Randomized Trial Examining the Benefit of Ultrasound in a Clinical Tight Control Regimen. Arthritis and Rheumatology 2018; 70(8):1192-1199. doi: $10.1002 / 40494$.

40. Ammitzbøll-Danielsen M, Østergaard M, Fana V, Glinatsi D, Naredo E et al. Intramuscular versus ultrasound-guided intratenosynovial glucocorticoid injection for tenosynovitis in 
patients with rheumatoid arthritis: a randomised, double-blind, controlled study. Annals of the Rheumatic Diseases 2017; 76(4):666-672. doi: 10.1136/ 2016-209840.

41. Hartung W, Ehrenstein B, Härle P, Fleck M, Weigand T. Ultrasound-guided joint injections in patients with rheumatic diseases. Zeitschrift für Rheumatologie 2011; 70(6):455-461. doi: 10.1007/s00393-011-0837-z.

42. Gutierrez M, Di Matteo A, Rosemffet M, Cazenave T, Rodriguez-Gil G et al. Short-term efficacy to conventional blind injection versus ultrasound-guided injection of local corticosteroids in tenosynovitis in patients with inflammatory chronic arthritis: A randomized comparative study. Joint Bone Spine 2016; 83(2):161-166. doi: 10.1016/ 2015.04.017.

43. Nguyen H, Ruyssen-Witrand A, Gandjbakhch F, Constantin A, Foltz V et al. Prevalence of ultrasound-detected residual synovitis and risk of relapse and structural progression in rheumatoid arthritis patients in clinical remission: a systematic review and meta-analysis. Rheumatology (Oxford) 2014; 53(11):2110-2118. doi: 10.1093/rheumatology/217.

44. Haavardsholm EA, Aga AB, Olsen IC, Lillegraven S, Hammer HB et al. Ultrasound in management of rheumatoid arthritis: ARCTIC randomised controlled strategy trial. British Medical Journal 2016; 354:i4205. doi: 10.1136/4205.

45. Paulshus Sundlisæter N, Aga AB, Olsen IC, Hammer HB, Uhlig T et al. Clinical and ultrasound remission after 6 months of treat-to-target therapy in early rheumatoid arthritis: associations to future good radiographic and physical outcomes. Annals of the Rheumatic Diseases 2018; 77(10):1421-1425. doi: 10.1136/ 2017-212830.

46. Colebatch AN, Edwards CJ, Østergaard M, van der Heijde D, Balint PV et al. EULAR recommendations for the use of imaging of the joints in the clinical management of rheumatoid arthritis. Annals of the Rheumatic Diseases 2013; 72(6):804-814. doi: 10.1136/ 2012-203158. 
47. Braun J, Baraliakos X, Buehring B, Kiltz U, Fruth M. Imaging of axial spondyloarthritis. New aspects and differential diagnoses. Clinical and Experimental Rheumatology 2018; 36 Suppl 114(5):35-42.

48. Mandl P, Navarro-Compán V, Terslev L, Aegerter P, van der Heijde D et al. EULAR recommendations for the use of imaging in the diagnosis and management of spondyloarthritis in clinical practice. Annals of the Rheumatic Diseases 2015; 74(7):1327-1339. doi: 10.1136/ 2014-206971.

49. Gutierrez M, Filippucci E, De Angelis R, Filosa G, Kane D et al. Sonographic spectrum of psoriatic arthritis: "the five targets". Clinical Rheumatology 2010; 29(2):133-142. doi: 10.1007/s10067-009-1292-y.

50. Lehtinen A, Taavitsainen M, Leirisalo-Repo M. Sonographic analysis of enthesopathy in the lower extremities of patients with spondylarthropathy. Clinical Exprimental Rheumatology $1994 ; 12: 143-148$.

51. Schett G, Lories RJ, D'Agostino MA, Elewaut D, Kirkham B et al. Enthesitis: from pathophysiology to treatment. Nature Reviews Rheumatology 2017; 13(12):731-741. doi: 10.1038/ 2017.188.

52. D'Agostino MA. Enthesitis detection by ultrasound: where are we now? Clinical and Experimental Rheumatology 2018;36 Suppl 114(5):127-130.

53. Naredo E, Möller I, de Miguel E, Batlle-Gualda E, Acebes C et al. High prevalence of ultrasonographic synovitis and enthesopathy in patients with psoriasis without psoriatic arthritis: a prospective case-control study. Rheumatology (Oxford) 2011; 50(10):1838-1848. doi: 10.1093/rheumatology078. 
54. Zabotti A, Bandinelli F, Batticciotto A, Scirè CA, Iagnocco A et al. Musculoskeletal ultrasonography for psoriatic arthritis and psoriasis patients: a systematic literature review. Rheumatology (Oxford) 2017; 56(9):1518-1532. doi: 10.1093/rheumatology179.

55. Balint PV, Terslev L, Aegerter P, Bruyn GAW et al. Reliability of a consensus-based ultrasound definition and scoring for enthesitis in spondyloarthritis and psoriatic arthritis: an OMERACT US initiative. Annals of the Rheumatic Diseases 2018; 77(12):1730-1735. doi: 10.1136/ 2018-213609.

56. Christiansen SN, Østergaard M, Terslev L. Ultrasonography in gout: utility in diagnosis and monitoring. Clinical and Experimental Rheumatology 2018; 36 Suppl 114(5):61-67.

57. Grassi W, Meenagh G, Pascual E, Filippucci E. "Crystal clear"-sonographic assessment of gout and calcium pyrophosphate deposition disease. Semin Arthritis Rheumatology 2006; 36(3):197-202. doi: 10.1016/ 2006.08.001.

58. Terslev L, Gutierrez M, Christensen R, Balint PV, Bruyn GA et al. Assessing Elementary Lesions in Gout by Ultrasound: Results of an OMERACT Patient-based Agreement and Reliability Exercise. Journal Rheumatology 2015; 42(11):2149-2154. doi: 10.3899/ 150366.

59. Neogi T, Jansen TL, Dalbeth N, Fransen J, Schumacher HR et al. 2015 Gout classification criteria: an American College of Rheumatology/European League Against Rheumatism collaborative initiative. Annals of the Rheumatic Diseases 2015; 74(10):1789-1798. doi: $10.1136 / 2015-208237$.

60. Gutierrez M, Schmidt WA, Thiele RG, Keen HI, Kaeley GS et al. International Consensus for ultrasound lesions in gout: results of Delphi process and web-reliability exercise. Rheumatology (Oxford) 2015; 54(10):1797-1805. doi: 10.1093/rheumatology/112. 
61. Ottavianı S, Richette P, Allard A, Ora J, Bardın T. Ultrasonography in gout: A case-control study. Clinical and Experimental Rheumatology 2012; 30(4):499-504.

62. Thiele Rg, Schlesinger N. Diagnosis of gout by ultrasound. Rheumatology (Oxford) 2007; 46(7):1116-1121. doi: 10.1093/rheumatology/058.

63. Wright SA, Filippucci E, McVeigh C, Grey A, McCarron M et al. High-resolution ultrasonography of the first metatarsal phalangeal joint in gout: a controlled study. Annals of the Rheumatic Diseases 2007; 66(7):859-864. doi: 10.1136/2006.062802.

64. Dalbeth N, Clark B, Gregory K, Gamble G, Sheehan T et al. Mechanisms of bone erosion in gout: a quantitative analysis using plain radiography and computed tomography. Annals of the Rheumatic Diseases 2009; 68(8):1290-1295. doi: 10.1136/ 2008.094201.

65. Peiteado D, Villalba A, Martın-Mola E, Balsa A, Demıguel E. Ultrasound sensi-tivity to changes in gout: a longitudinal study after two years of treatment. Clinical Experimental Rheumatology 2017; 35(5):746-751. Epub 2017 Mar 3.

66. Filippucci E, Ciappetti A, Grassi W. Sonographic monitoring of gout. Reumatismo 2003;55(3):184-186. doi: 10.4081/ 2003.184.

67. Sofka CM, Adler RS, Cordasco FA. Ultrasound diagnosis of chondro-calcinosis in the knee. Skeletal Radiology 2002; 31(1):43-45. doi: 10.1007/s002560100434.

68. Gutierrez M, Di Geso L, Salaffi F, Carotti M, Girolimetti R et al. Ultrasound detection of cartilage calcification at knee level in calcium pyrophosphate deposition disease. Arthritis Care Research (Hoboken) 2014; 66(1):69-73. doi: 10.1002/ 22190.

69. Filippou G, Frediani B, Gallo A, Menza L, Falsetti P et al. A "new" technique for the diagnosis of chondrocalcinosis of the knee: sensitivity and specificity of high-frequency 
ultrasonography. Annals of the Rheumatic Diseases 2007; 66(8):1126-1128. doi: 10.1136/ 2007.069344.

70. Filippou G, Scirè CA, Adinolfi A, Damjanov NS, Carrara G et al. Identification of calcium pyrophosphate deposition disease (CPPD) by ultrasound: reliability of the OMERACT definitions in an extended set of joints-an international multiobserver study by the OMERACT Calcium Pyrophosphate Deposition Disease Ultrasound Subtask Force. Annals of the Rheumatic Diseases 2018; 77(8):1194-1199. doi: 10.1136/ 2017-212542.

71. Vele P, Simon SP, Damian L, Felea I, Muntean L et al. Clinical and ultrasound findings in patients with calcium pyrophosphate dihydrate deposition disease. Medical Ultrasonography 2018; 20(2):159-163. doi: 10.11152/ 1193.

72. Scheel AK, Matteson EL, Dasgupta B, Bruyn GA, Ohrndorf S et al. Reliability exercise for the polymyalgia rheumatica classification criteria study: the oranjewoud ultrasound substudy. International Journal of Rheumatology 2009;7 38931. doi: 10.1155/2009/738931.

73. Dasgupta B, Cimmino MA, Kremers HM, Schmidt WA, Schirmer M et al. 2012 Provisional classification criteria for polymyalgia rheumatica: a European League Against Rheumatism/American College of Rheumatology collaborative initiative. Arthritis and Rheumatology 2012; 64(4):943-954. doi: 10.1002/ 34356.

74. Iagnocco A, Naredo E. Ultrasound of the osteoarthritic joint. Clinical and Experimental Rheumatology 2017; 35(3):527-534.

75. Sakellariou G, Conaghan PG, Zhang W, Bijlsma JW, Boyesen P et al. EULAR recommendations for the use of imaging in the clinical management of peripheral joint osteoarthritis. Annals of the Rheumatic Diseases 2017; 76(9):1484-1494. doi: 10.1136/annrheumdis-2016-210815. 
76. Dejaco C, Ramiro S, Duftner C, Besson FL, Bley TA et al. EULAR recommendations for the use of imaging in large vessel vasculitis in clinical practice. Annals of the Rheumatic Diseases 2018; 77(5):636-643. doi: 10.1136/ 2017-212649.

77. Schmidt WA, Blockmans D. Use of ultrasonographyand positron emission tomography in the diagnosisand assessment of large-vessel vasculitis. Current Opinion Rheumatology 2005; 17(1):9-15. doi: 10.1097/01. 0000147282.02411.c6.

78. Goules AV, Tzioufas AG. Imaging: diagnostic value of ultrasonography in Sjogren's syndrome. Nature Reviews Rheumatology 2014; 10(8):450-452. doi: 10.1038/ 2014.86.

79. Ch'ng SS, Roddy J, Keen HI. A systematic review of ultrasonography as an outcome measure of skin involvement in systemic sclerosis. International Journal of Rheumatic Diseases 2013; 16(3):264-272. doi: 10.1111/1756-185X.12106.

80. Peluso G, Bosello SL, Gremese E, Mirone L, Di Gregorio F et al. Detection of bone erosions in early rheumatoid arthritis: 3D ultrasonography versus computed tomography. Clinical Rheumatology 2015; 34(7):1181-1186. doi: 10.1007/s10067-015-2938-6.

81. Gutierrez M, Okano T, Reginato AM, Cazenave T, Ventura-Rios L et al. New Ultrasound Modalities in Rheumatology. Journal Clinical Rheumatology 2015;21(8):427-434. doi: 10.1097/ 0000000000000319.

82. Scheel AK, Schmidt WA, Hermann KG, Bruyn GA, D'agostino MA et al. Interobserverreliability of rheumatologists performing musculoskeletalultrasonography: results from a EULAR "Trainthe Trainers" course. Annals of the Rheumatic Diseases 2005; 64(7):1043-1049. doi: 10.1136/ 2004.030387. 
Table 1 : US image color scale

\begin{tabular}{|l|l|l|}
\hline & Anechoic & \multicolumn{2}{l|}{ Fluids, articular cartilage } \\
\hline & hypoechoic & Synovial Tissue, Muscle Fibrils*, Nerve* \\
\hline & hyperechoic & Bone, Tendon*, Fat, calcification, fibrocartilage* \\
\hline
\end{tabular}

* It can vary depending on the reflection of sound waves and surrounding tissues.

Table 2: US semicantitive scoring, gray scale and PD scale combined evaluation

\begin{tabular}{|l|l|l|l|}
\hline & & Gray skala & Power dopler(synovium) \\
\hline Grade 0 & Normal & 0 & 0 \\
\hline Grade 1 & Mild & 1 & $\leq 1$ \\
\hline Grade 2 & Moderate & 2 & $\leq 2$ \\
\hline Grade 3 & Severe & 3 & $\leq 3$ \\
\hline
\end{tabular}




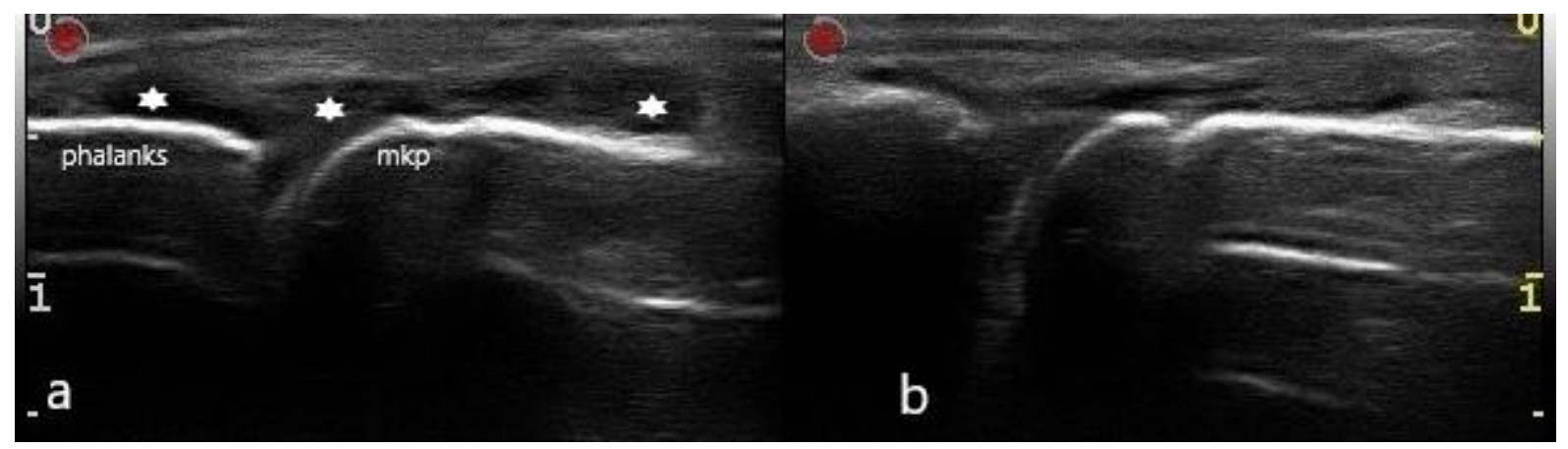

Figure 1: a Anechoic effusion in the second MCF joint in a RA patient(a), and fluid disappeared when pressure(b) was applied to the skin with a US probe. ( asterisks: synovial fluid, mkp: metacarpophalangeal)

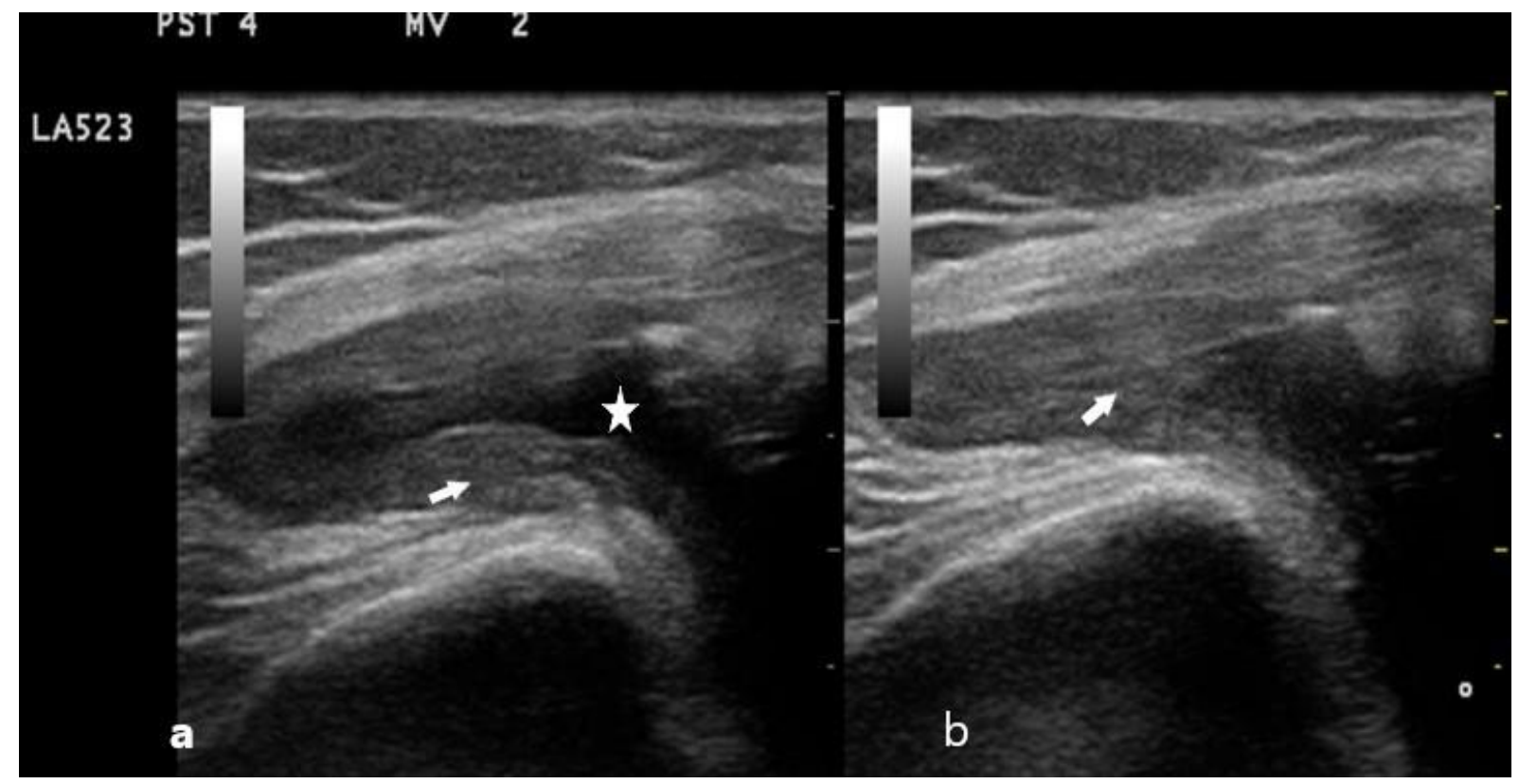

Figure 2: The joint fluid has disappeared with compression(a), but the synovial tissue is not displaced and has a hypoechoic appearance(b). (asterisks: synovial fluid, arrow: synovial hypertrophy ) 


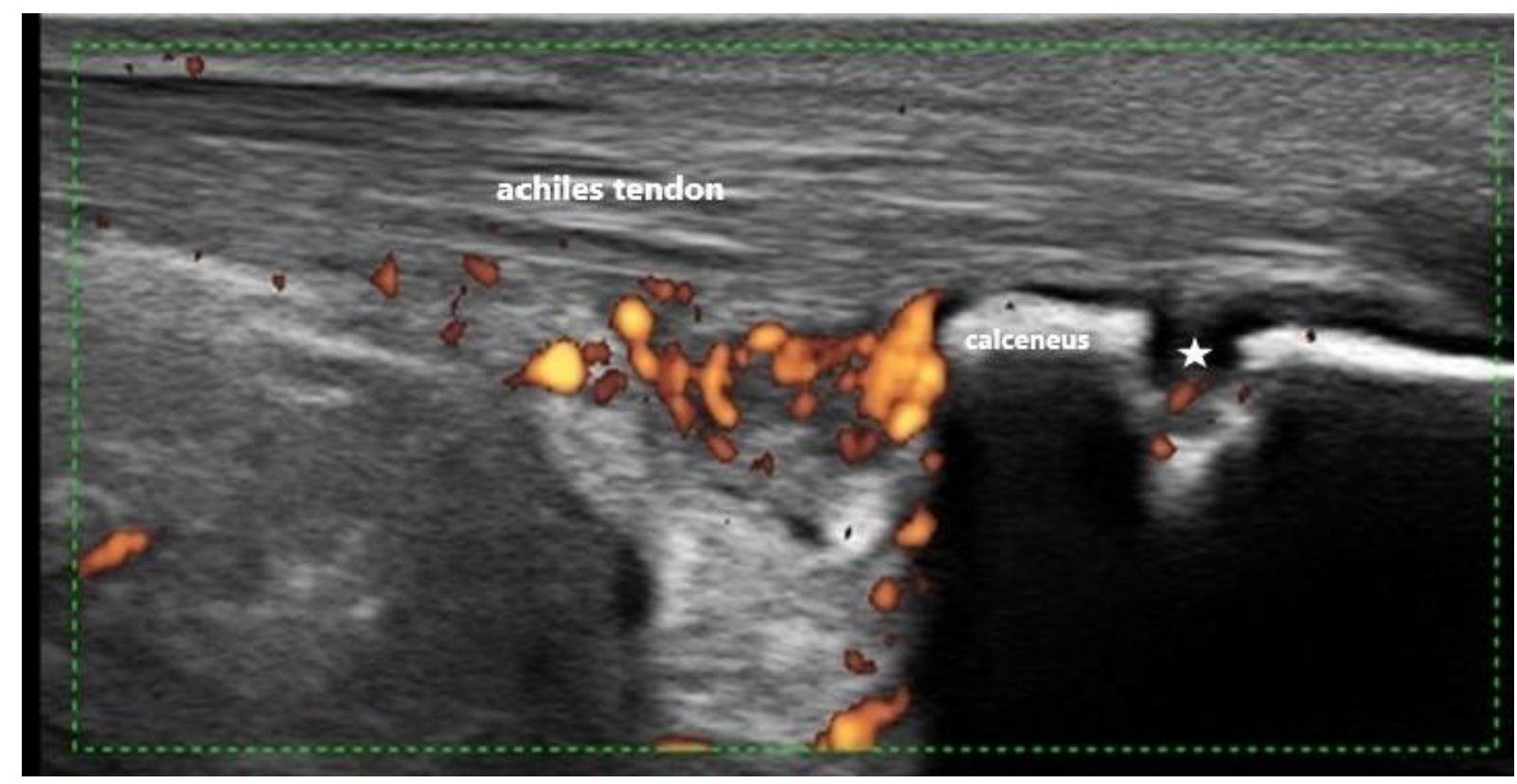

Figure 3: Thickening of the tendon and a hypoechoic appearance at the Achilles attachment site, calcaneal erosion and increased doppler activity involving the retrocalcaneal area. (asterisks: calcaneal erosion)
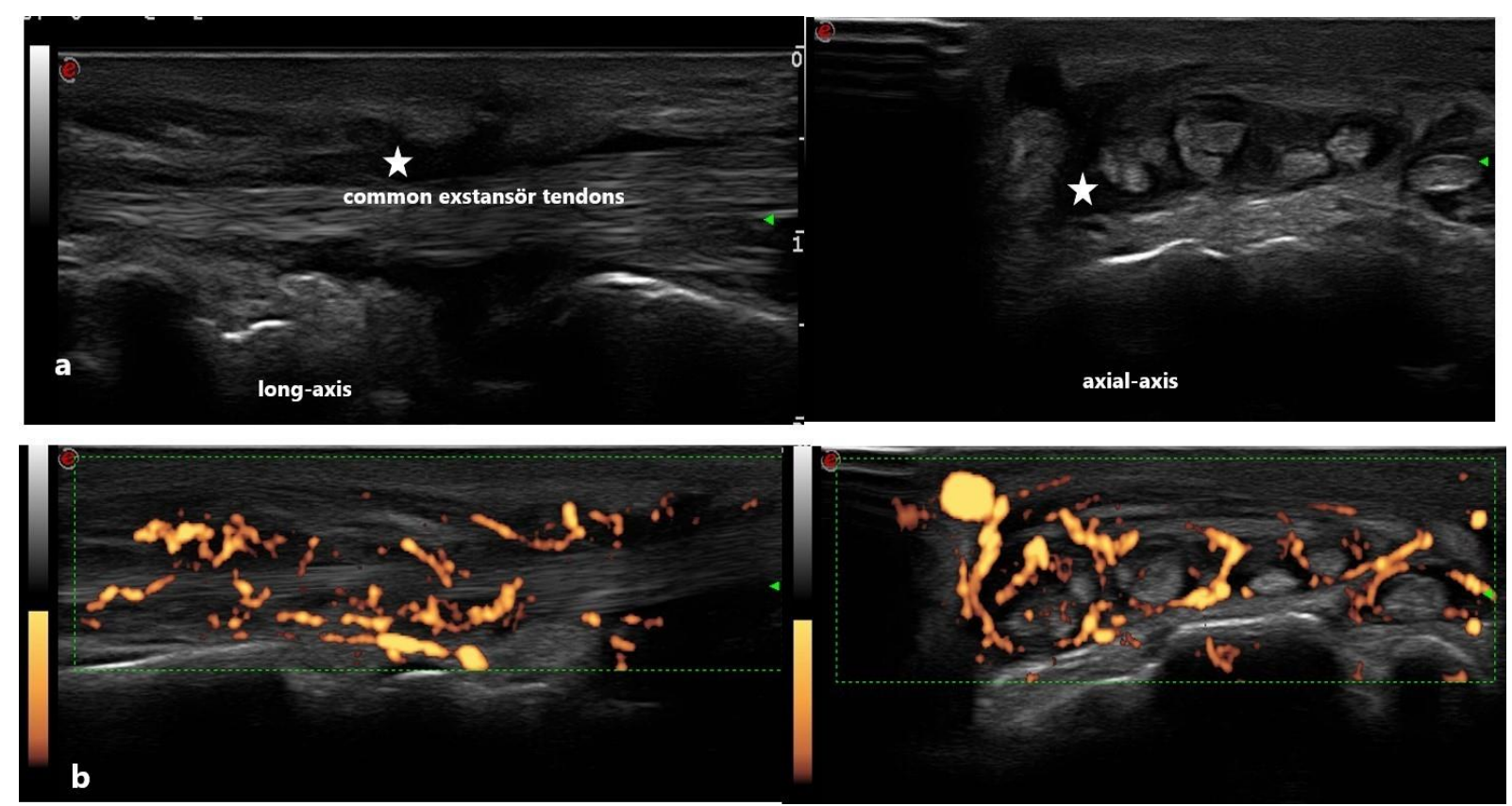

Figure 4: Tenosynovitis image of RA patient at wrist level. Active (grade 3) tenosynovitis case with both axial and longitunal gray(a) and doppler scales(b).( asterisks: synovial fluid) 


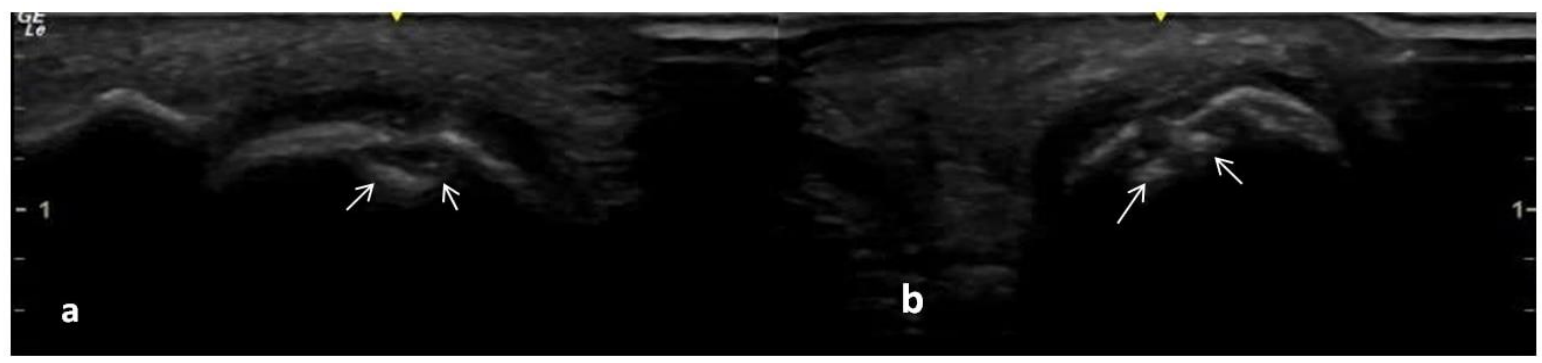

Figure 5: Erosion in the foot 5. MTF joint of an early RA patient. Cortical continuity deterioration in two planes ( a: longitudinal, b:transversal scans), arrow: erosion)

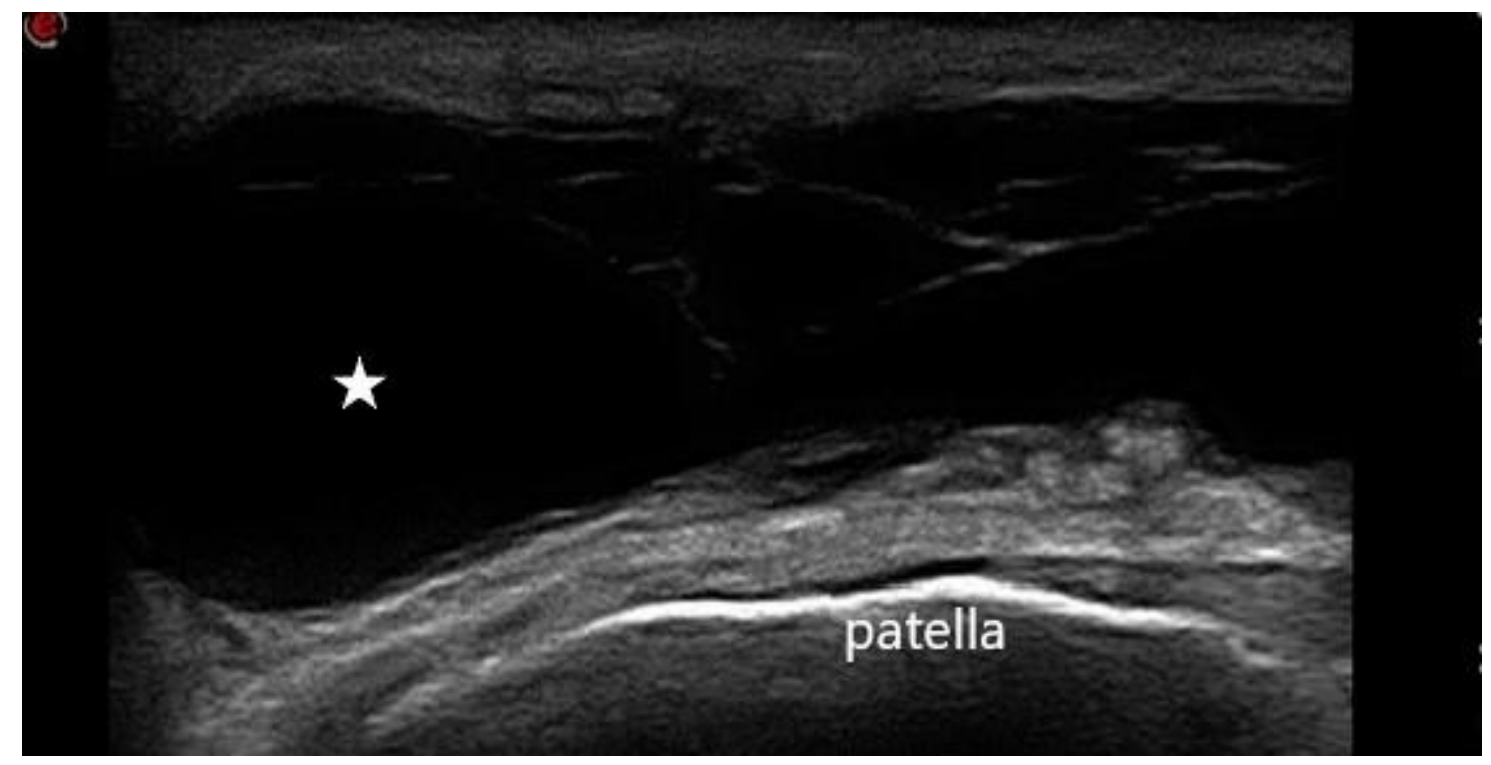

Figure 6: The image of a 42-year-old patient with complaints of pain and swelling in the knee and diagnosed with US Prepatellar bursitis. Hypoechoic line patella below, bursa image containing anechoic fluid material above the patella. (asterisks: synovial fluid) 


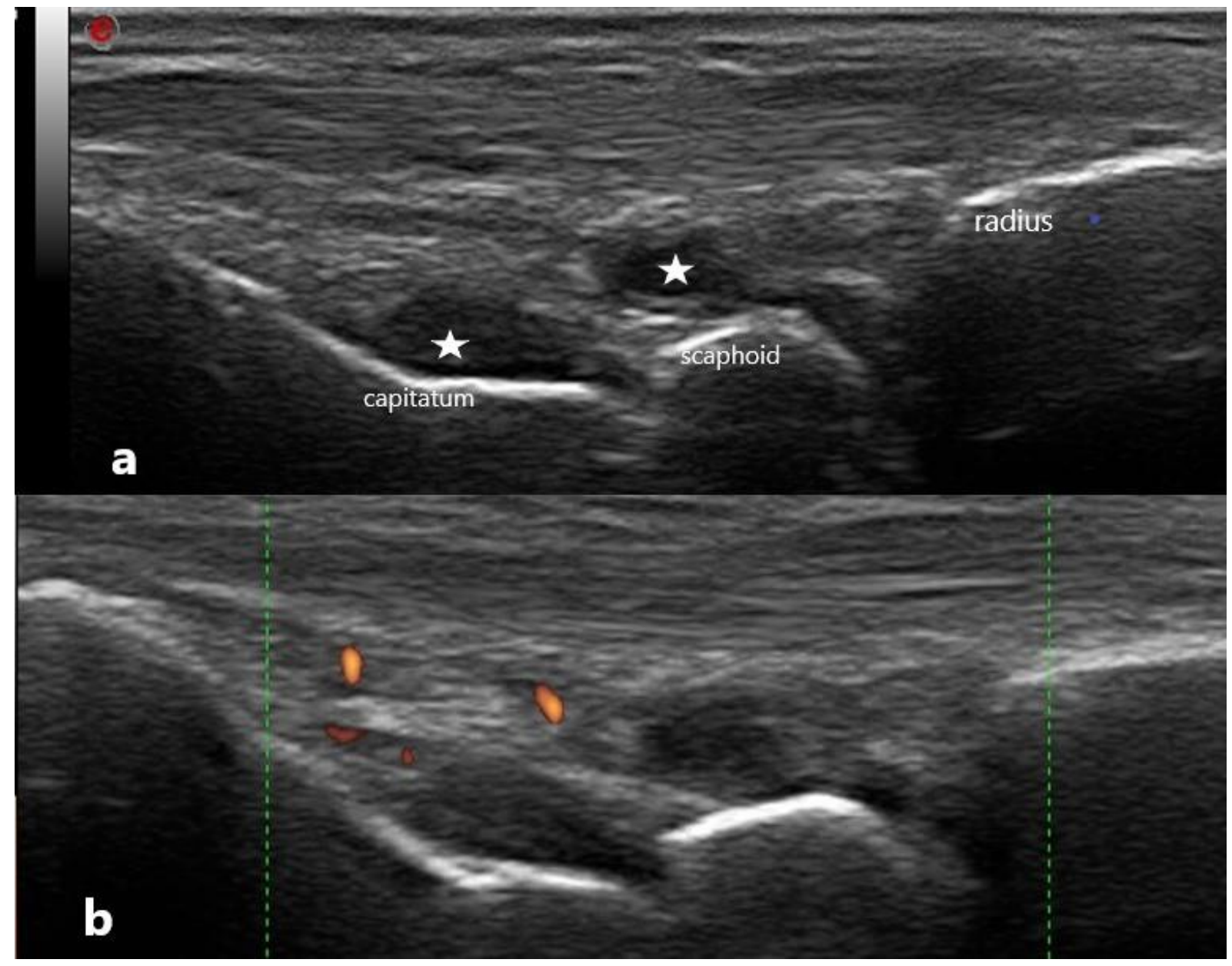

Figure 7: 36 years old, with a diagnosis of RA for 5 years, with no joint complaints using Metotrexate $20 \mathrm{mg} /$ week and Hydroxychloroquine 200mg / day. No sensitive and swollen joints, Sedim 2mm / s, CRP $0.1 \mathrm{mg} / \mathrm{dl}$. US image of the wrist of the patient with DAS 28 ESR: 0.49 SDAI: 2 CDAI: 2 (clinically in remission). Fluid in the gray scale(a) joint space, weak doppler signal on wrist(b). A patient clinically in remission but sonographically not in remission. (asterisks: synovial fluid) 


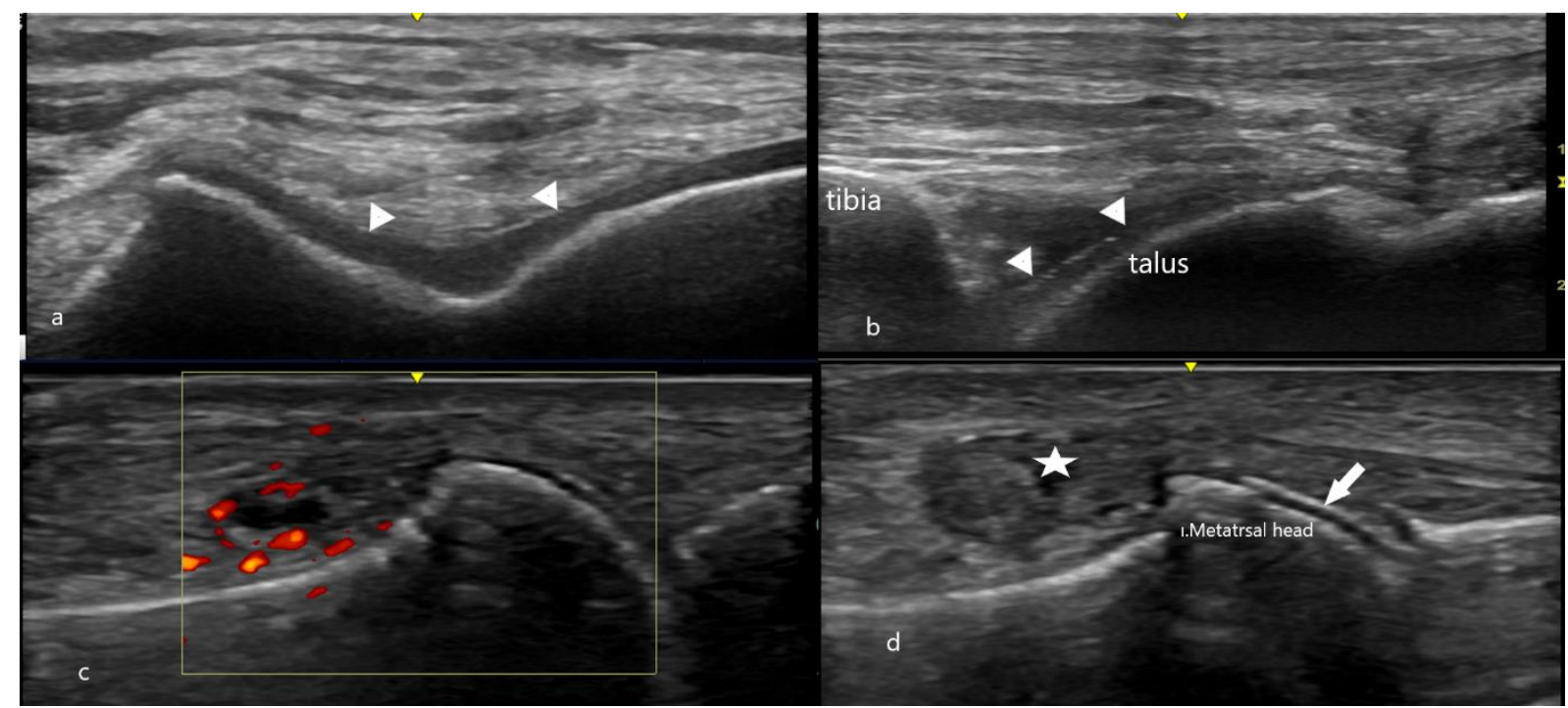

Figure 8: MSU crystals deposited on the cartilage surface, distal femur cartilage (a), talus cartilage(b), active gout arthritis, positive doppler signal (c), Double contours seen in 1. MTF joint in a gout patient(d) (arrowhead: double contours, asterisks: snowstorm)

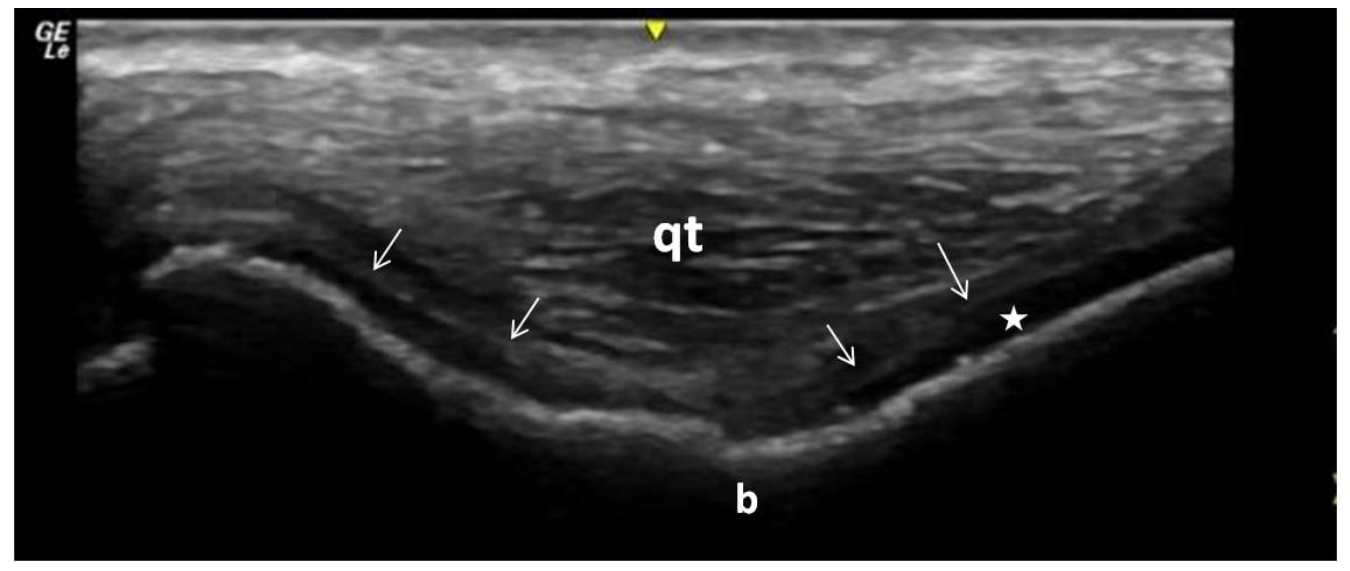

Figure 9: Calcium pyrophosphate dihydrate crystals accumulated in the hyaline and fibrocartilage in the knee joint. These crystals accumulate mostly inside the cartilage, unlike gout.( asterisks: cartilage, arrow: Calcium pyrophosphate dihydrate crystals, b:distal femur bone) 


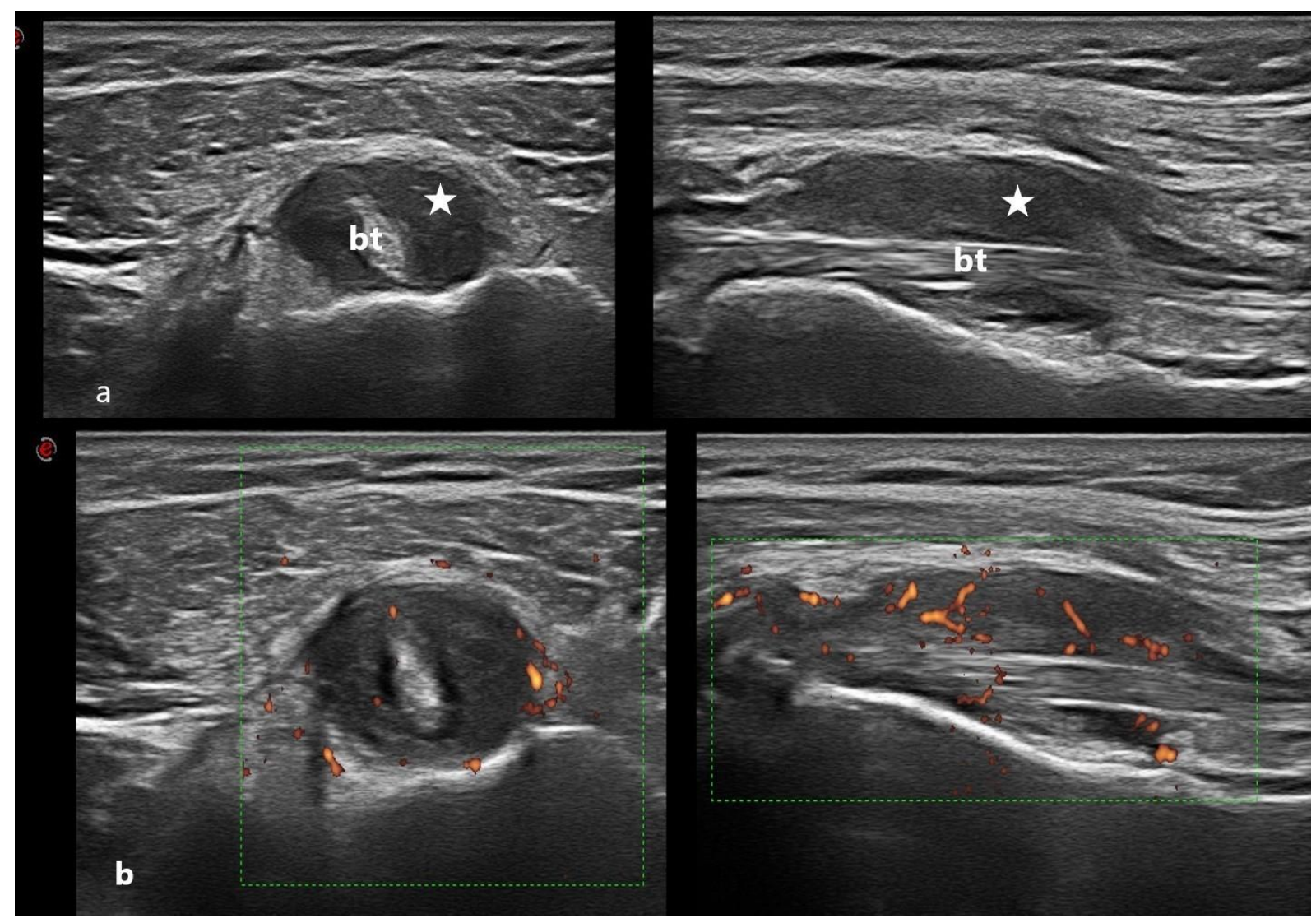

Figure 10: On shoulder US performed with PMR diagnosis, a patient with edema and anechoic effusion area around the shoulder with thickened biceps tendon in both planes (axial and longitinal) gray(a) and doppler scale(b) . (asterisks: synovial hypertrophy, bt :biceps tendon ) 


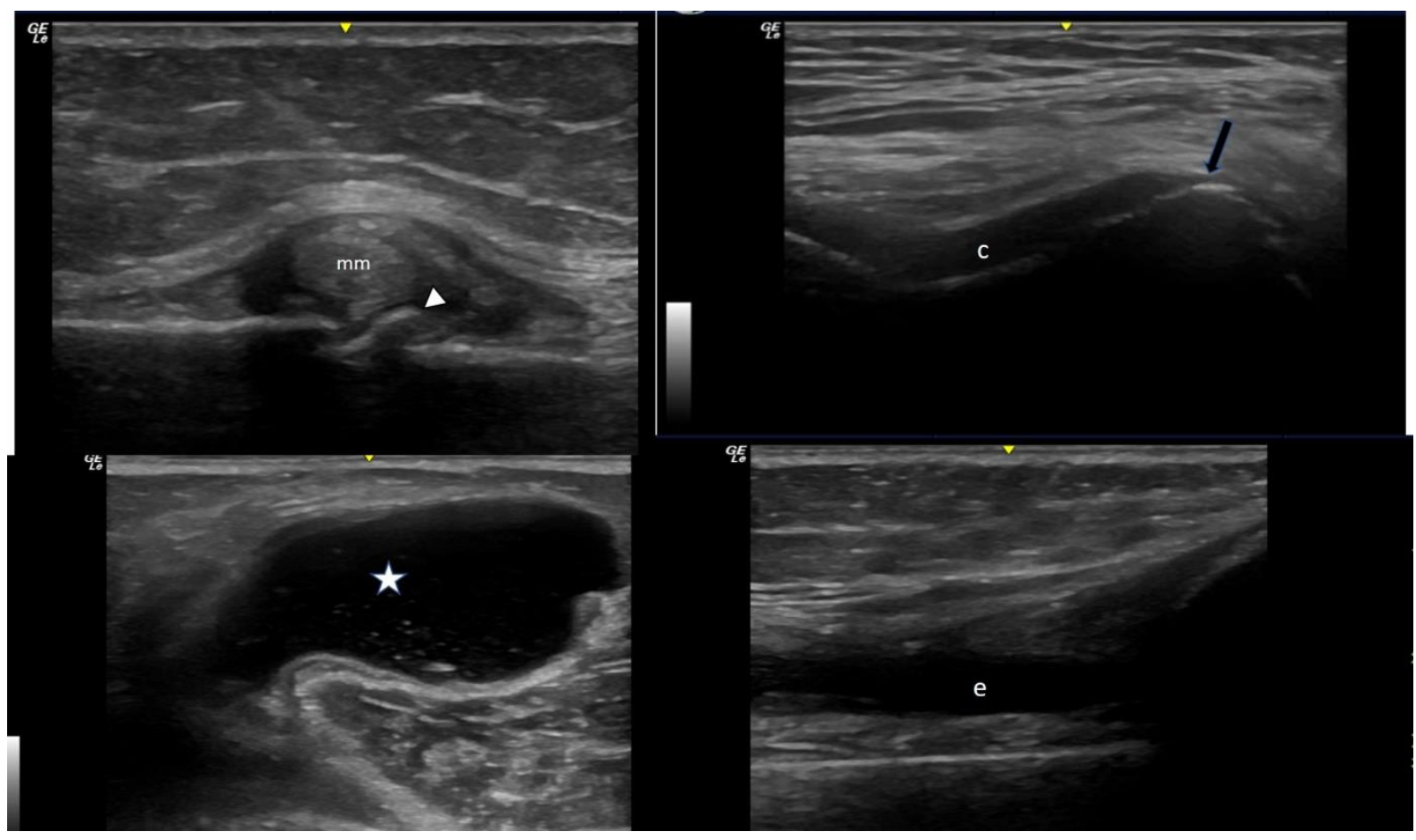

Figure 11: Sonographic findings in knees OA were osteophytes(white arrowheads), Suprapatellar effusion (e), protrusion of the medial meniscus(mm) with displacement of the medial collateral ligament, Baker's cyst(asterisk) and decreased cartilage(c) thickness(arrow) 


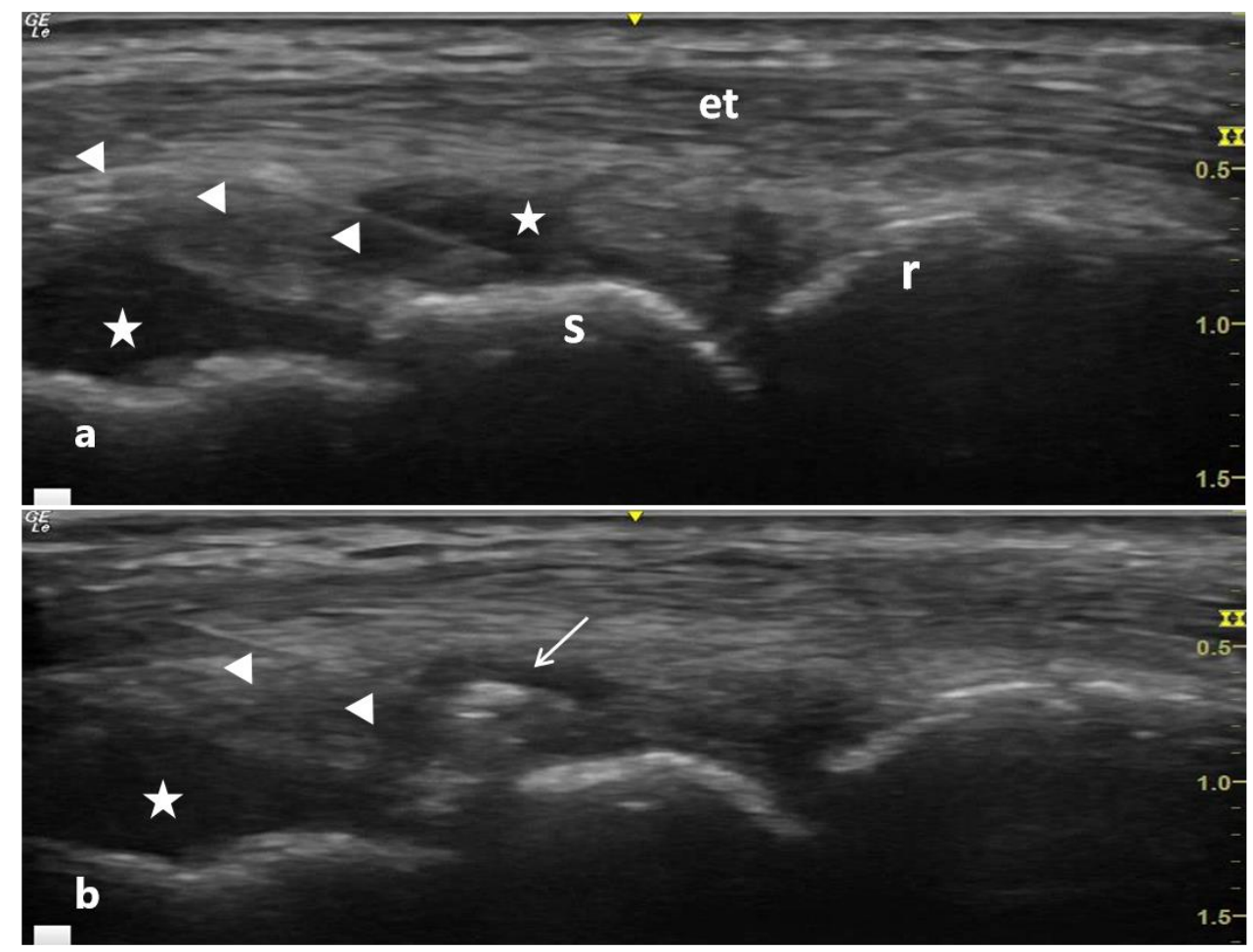

Figure 12: Wrist injection in Rheumatoid Arthritis patients(a). r (radius), s(scaphoid), arrowhead:needl, asterisks: synovial fluid, arrow: postinjection steroid crystal deposits(b). 